\title{
IFN- $\alpha$-driven CCL2 production recruits inflammatory monocytes to infection site in mice
}

\author{
CD Conrady ${ }^{1}, \mathrm{M} \mathrm{Zheng}^{2}, \mathrm{NA} \mathrm{Mandal}^{2}, \mathrm{~N}^{\mathrm{van}}$ Rooijen $^{3}$ and DJJ Carr ${ }^{1,2}$
}

\begin{abstract}
Herpes simplex virus type 1 (HSV-1) is the leading cause of corneal blindness in the developed world due to reactivation of infectious virus and the subsequent immune response. The innate response that facilitates viral control in the cornea is currently unknown. In the present study using a mouse chimera model, we found that a bone marrow component is crucial in inhibiting viral replication and identified inflammatory monocytes $\left(\mathrm{F} 4 / 80^{+} \mathrm{Gr}^{+}\right)$as the responsible cell. CCL2 was critical for recruiting inflammatory monocytes, and a loss of this chemokine in CCL2 ${ }^{-/-}$mice resulted in a loss of viral containment and inflammatory monocyte recruitment. To confirm these results, clodronate depletion of inflammatory monocytes resulted in elevated viral titers. Furthermore, siRNA targeting the innate sensor p204/IFI-16 resulted in a loss of CCL2 production. In conclusion, CCL2 expression driven by IFI-16 recognition of HSV-1 facilitates the recruitment of inflammatory monocytes into the cornea proper to control viral replication.
\end{abstract}

\section{INTRODUCTION}

Herpes simplex virus type I (HSV-1) is a double-stranded DNA virus of which $60-90 \%$ of the adult population is seropositive. ${ }^{1}$ The pathogen is of significant clinical interest due to its role in inducing morbidity in the central nervous system and cornea. ${ }^{1}$ HSV-1 is spread through mucocutaneous contact in which the virus will first establish a lytic infection in epithelial tissue and progress to invading local sensory fibers. Once the virus has gained access to sensory neurons, it is then transported in a retrograde fashion to the cell body housed in local neural ganglia. In the case of initial oropharyngeal infection, HSV-1 will be transported to the trigeminal ganglia where it can persist as a latent infection indefinitely. ${ }^{2}$

Following reactivation of HSV-1, infectious virions travel in an anterograde fashion towards sites innervated by divisions of the trigeminal nerve such as the cornea. Recurrent reactivation can then initiate an inflammatory event that if perpetuated can lead to significant corneal scaring known as herpetic keratitis. ${ }^{3}$ In individuals who have had an viral reactivation in the cornea, the chance of subsequent reactivations drastically increases, whereas cornea graft survival drops. ${ }^{4}$ Thus, identifying mechanisms to inhibit viral replication and establishment of HSV latency could drastically reduce the incidence of herpetic keratitis.

Unfortunately, highly effective anti-viral compounds such as acyclovir and penciclovir block productive infection but do not reduce the establishment of latency..$^{5}$ In sites such as the skin, delayed responses of $\mathrm{CD} 8^{+} \mathrm{T}$ cells reduce the number of infected neurons as well as the amount of latent viral copies but do not thwart viral latency. ${ }^{6}$ These studies would suggest that neither a robust adaptive immune response nor antiviral drugs are effective in reducing initial infection of innervating ganglia to the point of blocking the establishment of latency. Our lab as well as others have shown that type I interferon (IFN) production is critical in preventing viral dissemination and subsequent death of the host. ${ }^{7,8}$ Thus, identification of other important innate mechanisms in acute control of viral replication could be tailored to help inhibit HSV replication during the primary infection and prevent establishment of latency in the trigeminal ganglia.

IFI-16/p204 has recently been identified as the innate sensor facilitating the acute anti-viral state of the cornea and other epithelial tissues to HSV by induction of IFN- $\alpha$ production. ${ }^{9} \mathrm{~A}$ loss of this critical protein or its downstream adaptor protein, STING, results in a significant rise in the viral titer. ${ }^{9}$ However, the role of infiltrating innate immune cells (e.g., natural killer (NK) cells, macrophages, and neutrophils) has not been evaluated relative to this sensor during acute infection. Infiltrating leukocytes, including granulocytes, monocytes/macrophages, and NK cells, are thought to contribute in the resistance to HSV1 infection by direct or indirect means. ${ }^{10-12}$ Specifically, NK

${ }^{1}$ Department of Microbiology, Immunology University of Oklahoma Health Sciences Center, Oklahoma City, OK, USA. ${ }^{2}$ Department of Ophthalmology, University of Oklahoma Health Sciences Center, Oklahoma City, OK, USA. ${ }^{3}$ Molecular Cell Biology and Immunology, VU Medical Center, Amsterdam, The Netherlands. Correspondence: DJJ Carr (dan-carr@ouhsc.edu) 
cells can directly target HSV-1-infected cells and target them for cytolysis. ${ }^{13}$ In a more indirect fashion, compounds released from immune cells such as nitric oxide (NO) have shown potent antiviral properties in cell culture. ${ }^{14}$ In the peripheral nervous system, macrophages secreting TNF- $\alpha$ (tumor necrosis factor $\alpha$ ), NO, and IFN- $\gamma$ control viral replication during the primary infection. ${ }^{15}$

Thus, we hypothesized that IFI-16/p204 recognition of HSV-1 was required to initiate signals to recruit bone marrow (BM)derived macrophages to the site of infection and contain acute viral replication. Consistent with this hypothesis, we found that IFI-16-driven, IFN- $\alpha$ production initiated inflammatory monocyte recruitment to the site of infection in a CCL2-dependent manner. This response was a critical component of innate immunity in viral surveillance of the cornea.

\section{RESULTS}

\section{Resident cells and BM leukocytes contribute to HSV-1 surveillance in the cornea}

A functional type I IFN pathway is absolutely required for resistance to HSV-1 replication in the cornea as previously shown in IFN receptor A1-deficient mice, $\mathrm{CD} 118^{-/-}$, in which these mice no longer respond to IFN signals and rapidly succumb to viral dissimination. ${ }^{7,9}$ To dissect the contribution of resident (corneal stromal and epithelial cells) and BM-derived cells in the innate immune response to HSV-1 in the cornea, a chimera model was chosen to evaluate resistance using wild-type (WT) and highly sensitive $\mathrm{CD} 118^{-/-}$mice. The $48 \mathrm{~h}$ post-infection (pi) time point was chosen as this period appears to be the critical period in which HSV-1 exploits the cornea in the absence of a functional type I IFN pathway. ${ }^{9}$ Cornea samples from WTBM $>$ WT and $\mathrm{CD} 118^{-/-} \mathrm{BM}>\mathrm{WT}$ mice contained significantly less virus than $\mathrm{WTBM}>\mathrm{CD} 118^{-/-}$and $\mathrm{CD} 118^{-/-} \mathrm{BM}>\mathrm{CD} 118^{-/-}$mice, highlighting the importance of IFN-responsive corneal resident cells in HSV-1 containment (Figure 1). However, WTBM $>$ WT mouse corneas possessed significantly less virus than $\mathrm{CD} 118^{-/-}$ $\mathrm{BM}>\mathrm{WT}$ mouse corneas, implicating a role for BM-derived leukocytes in viral surveillance of the cornea in concert with IFN-responsive resident cells (Figure 1).

\section{Resident cell production of CCL2 drives inflammatory monocyte recruitment into the cornea}

To identify the innate leukocyte population(s) and thus, the BMderived component of viral surveillance in the cornea of mice that was implicated above, flow cytometric analysis of select infiltrating leukocytes was performed. Previously published work reported that viral containment in Toll-like receptor (TLR) adaptor protein-deficient mice mirrored that of WT controls in the cornea. ${ }^{9}$ Thus, it was hypothesized that the leukocyte population required for HSV containment would be similar in MyD88 ${ }^{-1-}$, Trif $^{-1-}$, and WT mice; however, recruitment of this specific cell type would be severely reduced in $\mathrm{CD} 118^{-/-}$corneas owing to their enhanced susceptibility to infection. Fortyeight hours pi, CD118 ${ }^{-/-}$mice exhibited a gross deficiency in NK cells $\left(\mathrm{CD}^{-}{ }^{-} \mathrm{NK} 1.1^{+}\right.$; Figure $\left.2 \mathbf{c}, \mathbf{g}\right)$ and inflammatory monocytes $\left(\mathrm{F} 4 / 80^{+} \mathrm{Gr}^{+} / \mathrm{CD}_{11} \mathrm{~b}^{+} \mathrm{Ly}_{6 \mathrm{C}^{+}} \mathrm{Ly}_{6 \mathrm{G}^{-}}\right.$; Figure 2d-f)

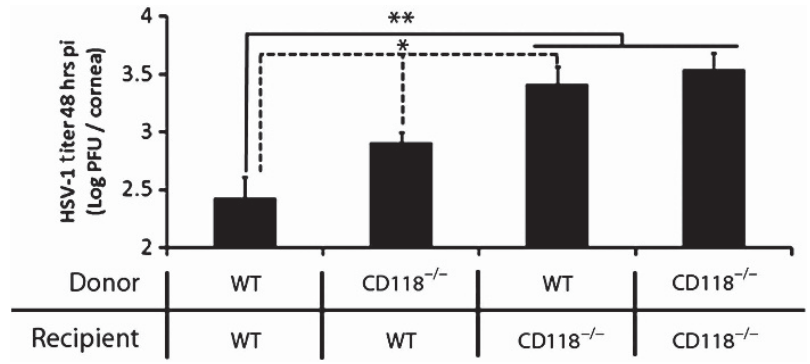

Figure 1 Corneal defense against herpes simplex virus type I (HSV-1) requires a bone marrow component. Chimeric mice were created with bone marrow cells from wild-type (WT) and CD118 ${ }^{-/-}$mice. Ten weeks after irradiation and bone marrow transfer, chimerism was confirmed by flow cytometric analysis of blood samples and was consistently $>95 \%$. Following infection with 1,000 PFU (plaque-forming units) HSV-1/eye, viral loads were measured $48 \mathrm{~h}$ post infection (pi) by plaque assay. Bars represent 2-4 experiments, $n=2-4$ per group per experiment and are expressed as the mean log PFU/cornea \pm s.e.m. ${ }^{* \star} P<0.01 ;{ }^{*} P<0.05$ when comparing all groups. Solid line, comparing WTBM $>$ WT mice with WTBM $>\mathrm{CD} 118^{-/-}$mice and $\mathrm{CD} 118^{-/-} \mathrm{BM}>\mathrm{CD} 118^{-/-}$mice; dotted line, comparing WTBM $>$ WT mice with $\mathrm{CD} 118^{-/-} \mathrm{BM}>\mathrm{WT}$ mice and $\mathrm{CD} 118^{-/-} \mathrm{BM}>\mathrm{WT}$ mice with WTBM $>\mathrm{CD} 118^{-/}-$mice.

residing in the cornea proper compared with all the other groups. By contrast, $\mathrm{CD} 118^{-/-}$mice possessed similar numbers of total leukocytes (CD45 hi; Figure 2a), macrophages (F4/80+ $\mathrm{Gr}^{-}$; data not shown), and neutrophils ( $\mathrm{F} 4 / 80^{-} \mathrm{Gr}^{+}$; Figure $2 \mathrm{~b}$ ) in the cornea compared with WT, MyD88 $8^{-1-}$, and Trif $^{-1-}$ mice. Taken together, these results suggested a potential role for inflammatory monocytes and/or NK cells in viral containment in the cornea $48 \mathrm{~h}$ pi, while further suggesting that the influx of neutrophils was not responsible for HSV surveillance.

In order to identify the predominant signal for inflammatory monocyte and NK cell recruitment into the infected cornea, chemokine levels of CXCL1, CCL2, and CCL5, known chemoattractants for early-responding leukocyte populations, ${ }^{16}$ were evaluated in TLR adaptor-deficient mice. In the absence of infection, CXCL1, CCL2, and CCL5 were below the level of detection in the cornea (data not shown). Forty-eight hours pi, there were no appreciable differences in CXCL1 production among all the groups (Figure 3a). Conversely, CCL5 expression levels were diminished, while CCL2 production was severely abated in CD118 $8^{-1-}$ mouse corneas compared with WT, MyD88 ${ }^{-1-}$, and Trif ${ }^{-1-}$ mice (Figure 3a). Furthermore, to negate TLR redundancy, DKO mouse chemokine production resembled that of Trif $^{-1-}$ and MyD88 $8^{-1-}$ mice (Figure 3a). Even though CCL2 production was significantly elevated in TLR adaptor-deficient mice compared with $\mathrm{CD} 118^{-/-}$mice, HSV1-infected MyD88 $8^{-/-}, \mathrm{DKO}$, and $\mathrm{Trif}^{-/-}$mice displayed lower levels of CCL2 compared with those of WT mice (Figure 3a). We interpret these results to suggest that TLR activation contributes to CCL2 production but additional pathways have the predominant role in response to HSV-1. By $72 \mathrm{~h}$ pi, high CCL2

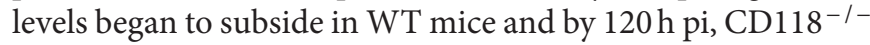
mice produced significantly more CCL 2 in the cornea than WT controls (Figure 3b). 

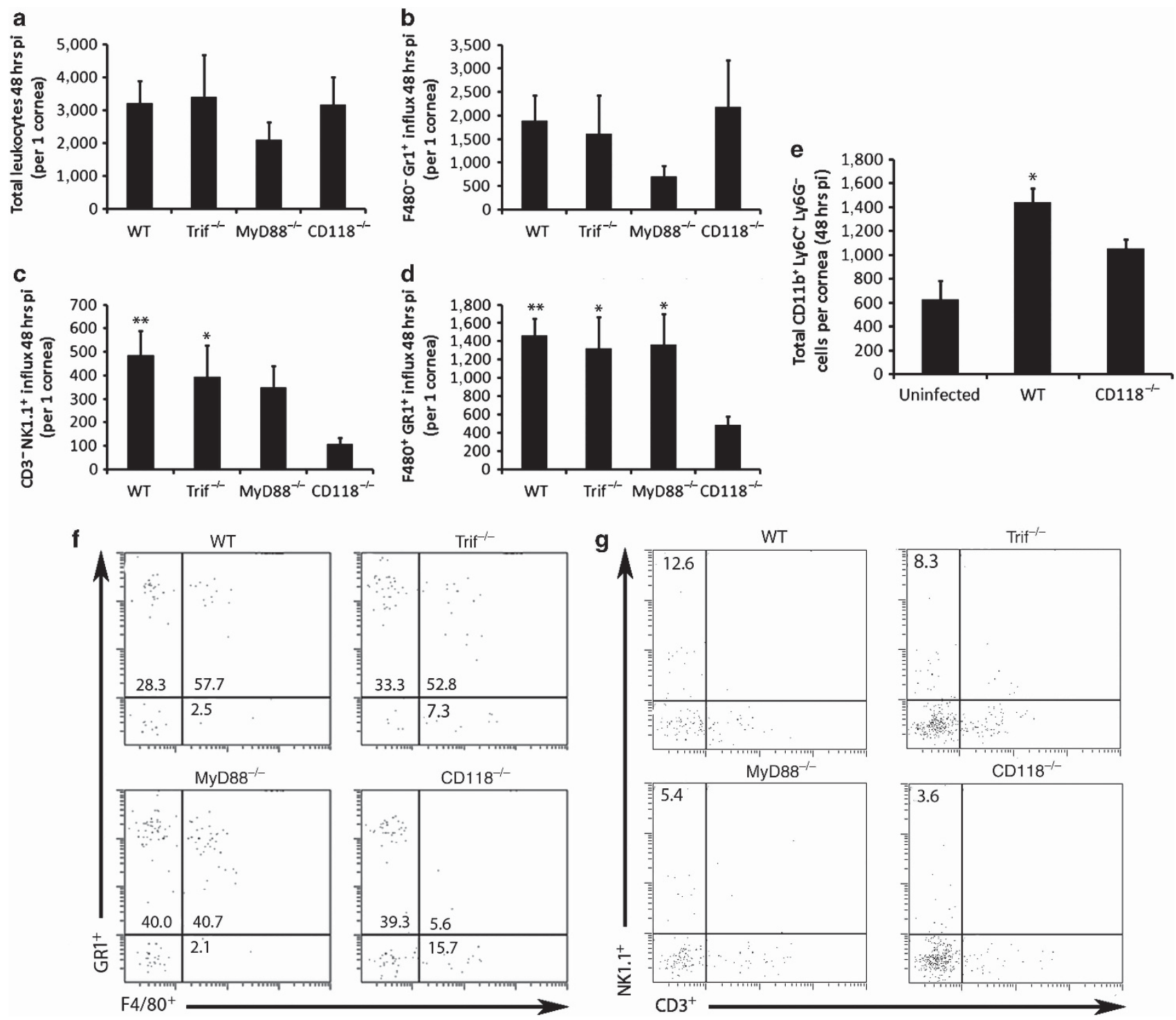

Figure $2 \mathrm{CD} 118^{-/-}$mice exhibit gross deficiencies in inflammatory monocyte and natural killer (NK) cell recruitment into the cornea. Forty-eight hours post infection (pi), corneas from HSV-1 (herpes simplex virus type I)-infected mice ( $n=6-10$ corneas/group) were harvested and subsequently digested in type I collagenase. Single cell suspensions were then stained with specific monoclonal antibodies to phenotypically identify infiltrating (a) CD45 hi total leukocytes, (b) F4/80- Gr1+ neutrophils, (c) CD3- NK1.1+ NK cells, and (d, e) F4/80+ Gr1+/CD11b+ Ly6C+ Ly6G- inflammatory monocytes by flow cytometry. Results summarize the mean phenotypic leukocyte count/cornea \pm s.e.m. of three independent experiments. ${ }^{* \star} P<0.01$; ${ }^{\star} P<0.05$ comparing all the groups with $\mathrm{CD}_{118^{-/-}}$. (f, $\left.\mathbf{g}\right)$ Representative histograms for F4/80+ $\mathrm{Gr} 1^{+}(\mathbf{f})$ and $\mathrm{CD} 3^{+} \mathrm{NK} 1.1^{+}(\mathbf{g})$ are depicted.

To localize the source of CCL2 production in the cornea, the previously described mouse model chimera was utilized. At $48 \mathrm{~h}$ pi, CCL2 levels were significantly elevated in WTBM $>$ WT and $\mathrm{CD} 118^{-/-} \mathrm{BM}>\mathrm{WT}$ mice compared with $\mathrm{WTBM}>\mathrm{CD} 118^{-/-}$ and $\mathrm{CD} 118^{-/-} \mathrm{BM}>\mathrm{CD} 118^{-/-}$mice establishing resident, IFN-responsive corneal cells as the primary source of CCL2 (Figure 3c). There was no significant difference between $\mathrm{CD} 118^{-/-}$mouse recipients of WT or CD118 ${ }^{-/-} \mathrm{BM}$ cells or between WT mouse recipients of WT or CD118 ${ }^{-1-}$ BM cells further emphasizing the importance of the resident population in CCL2 production (Figure 3c).

Previously, CCL2 had been shown to mediate NK cell trafficking and activity as well as macrophage recruitment to sites of infection and inflammation. ${ }^{17-19}$ However, its role in the cornea is poorly understood in relation to these cell types. Thus, we sought to elucidate the contribution of CCL2 production in viral surveillance of the cornea utilizing WT and CCL2-deficient $\left(\mathrm{CCL} 2^{-/-}\right)$mice. Consistent with our previous results, $\mathrm{CCL} 2^{-/-}$ mice suffered from a significant rise in infectious virus in the cornea compared with WT animals at $48 \mathrm{~h}$ pi but viral levels returned to those of WT controls $120 \mathrm{~h}$ pi, whereas more virus was recovered in the trigeminal ganglia 5 days pi (Figure 4a,b). Changes in replicating virus levels occurred despite similar numbers of NK cells (Figure 4c), neutrophils (Figure 4e), and total leukocytes in the cornea proper (data not shown). CCL2 levels were readily detectable in the cornea of WT mice compared with 
a
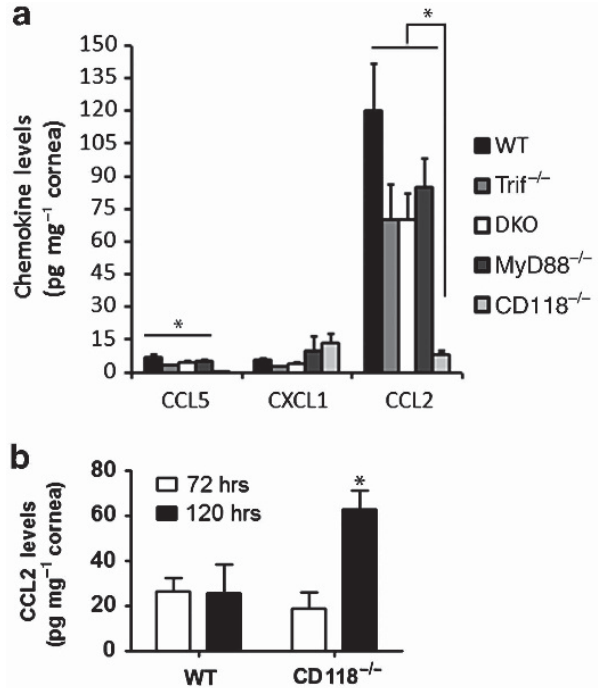

c

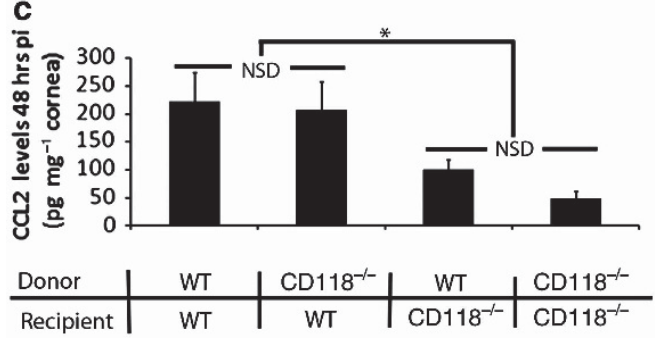

Figure 3 Early resident cell production of CCL2 is minimized in CD118 ${ }^{-/-}$mice. Corneas (4-10 corneas/group) were harvested from (a) infected TLR (Toll-like receptor) adaptor protein-deficient $48 \mathrm{~h}$ postinfection (pi), wild-type (WT) and (b) CD118 ${ }^{-/-}$mice 72 and $120 \mathrm{~h}$ pi , and (c) chimeric mice $48 \mathrm{~h}$ pi and evaluated for specific chemokine production by suspension arrays. Results represent $2-3$ independent experiments and are summarized as the mean $\mathrm{pg} \mathrm{mg}^{-1} \pm$ s.e.m. ${ }^{*} P<0.05$ when compared with CD $118^{-/-}$, WTBM $>\mathrm{CD} 118^{-/-}$or $\mathrm{CD} 118^{-/-}$ $\mathrm{BM}>\mathrm{CD} 118^{-/-}$. NSD, no significant difference.

$\mathrm{CCL}^{-1-}$ mice at this time point (Figure 4f). Furthermore, the activation status of NK cells (expression of NK cell activation marker, CD $94^{20,21}$ ) was similar in CCL2 ${ }^{-1-}$ and WT mice as well as mean fluorescent intensity (Figure 4d, data not shown). We interpreted these results to suggest NK cells were not the cell type responsible for immune surveillance of the cornea $48 \mathrm{~h}$ pi. Thus, the sensitivity of CCL2 $2^{-/-}$mice to HSV-1 infection of the cornea was assigned exclusively to a gross deficiency in the recruitment of inflammatory monocytes $\left(\mathrm{F} 4 / 80^{+} \mathrm{Gr} 1^{+}\right)$to the cornea (Figure 4e,g). To solidify the critical role of inflammatory monocytes, subconjunctival injections of clodronate liposomes were used to show a significant drop in viral containment associated with a loss of inflammatory monocytes in the cornea proper compared with those of phosphate-buffered saline (PBS)-liposome controls (Figure 5a,b). Although the clodronate liposome treatment resulted in a decrease in total neutrophils as well, previous data shown herein negated their contribution to ocular HSV immunity (Figure 2). Additionally, depletion of neutrophils did not result in an enhanced corneal susceptibility to HSV-1 infection consistent with previous findings in an HSV-1 flank infection model (Figure 6). ${ }^{22}$

\section{Inflammatory monocytes secrete NO to inhibit HSV-1}

\section{replication}

Inflammatory monocytes have been shown to restrict HSV-1 replication in vitro ${ }^{23}$ likely due to the secretion of antiviral compounds driven by IFN and nuclear factor (NF)- $\mathrm{kB}$ signaling such as NO. ${ }^{24,25}$ In order to test this hypothesis and to identify one likely key antiviral compound secreted by infiltrating activated monocytes, we had to first establish the presence or absence of inducible NO synthase (iNOS). Within $48 \mathrm{~h}$ pi, iNOS transcript levels in the cornea of both infected $\mathrm{CD} 118^{-/-}$and CCL2 ${ }^{-/-}$ mice were indistinguishable from uninfected controls (Figure 5c). In stark contrast, iNOS expression was elevated twofold in the cornea of WT animals. Furthermore, gel electrophoresis of RT-PCR (PCR with reverse transcriptase) products confirmed a reduction or absence of iNOS in uninfected CD118 ${ }^{-/-}$and WT mouse corneas (Figure $\mathbf{5} \mathbf{c}, \mathbf{d}$ ). To determine the significance of NO production in viral containment, HSV-1 levels were determined following iNOS inhibition with aminoguanidine. ${ }^{24}$ Viral titers were significantly elevated in aminoguanidine-treated mice compared with vehicle-treated WT controls $48 \mathrm{~h}$ pi (Figure 5e). Taken together, these results suggested a reduction of inflammatory monocyte migration into the corneas of $\mathrm{CD} 118^{-/-}$and CCL2 ${ }^{-/-}$mice results in the loss of the primary source of $\mathrm{NO}$ production and consequential rise in virus output.

\section{CCL2 production driven by IFN- $\alpha$}

We previously identified the innate sensor, p204/IFI-16, as the crucial regulator of IFN- $\alpha$ in response to HSV infection of the cornea and thus, hypothesized that signals such as CCL2 were induced by the sensor to recruit the BM arm of innate immunity. To first identify a potential role of IFI-16/p204 in CCL2 production, CCL2 transcript expression was evaluated $24 \mathrm{~h}$ pi in human corneal epithelial cells transfected with nonspecific siRNA or that directed to IFI- 16 . A loss of IFI-16 ( 70\% reduction $)^{9}$ resulted in a significant reduction in CCL2 mRNA transcript solidifying a role of the innate sensor in CCL2 production (Figure 7a). This was confirmed in vivo with mice deficient in the adaptor protein for IFI-16, STING, in which CCL2 levels mirrored those of $\mathrm{CD} 118^{-/-}$mice and were severely diminished compared with those of WT controls (Figure 7b). We interpret these results suggested that signals emanating from p204/IFI-16 were responsible for regulating CCL2 production.

IFI-16 has been shown to activate both NF- $\kappa B$ and IRF-3 (interferon regulatory factor 3)/IFN cascades, and CCL2 is a known NF- $\kappa \mathrm{B}$-driven chemokine through a phospholipase Cdependent mechanism. ${ }^{26,27}$ Both an IFN-stimulated regulatory element and NF- $\kappa B$ binding site are found upstream of the start site at position -580 to -566 and -490 to -480 , respectively (Figure 7c). To evaluate the role of NF- $\mathrm{KB}$ on CCL2 production, western blot analysis was performed on nuclear extracts on TLR adaptor protein-deficient mice to explain the differences seen in CCL2 production (Figure 3a). However, there were no appreciable differences between any of the groups tested, suggesting that NF- $\mathrm{\kappa B}$ activity was not responsible for CCL2 production $48 \mathrm{~h}$ pi (Figure $7 \mathrm{~d}$ ). To then evaluate the role of IFN, human corneal epithelial cells were treated with recombinant 
a

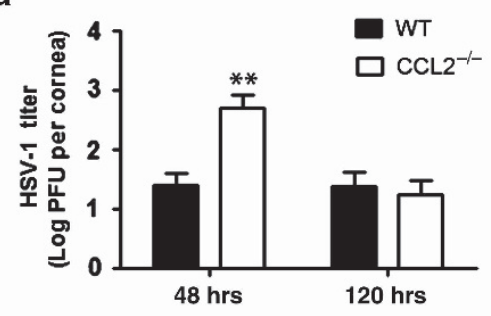

C

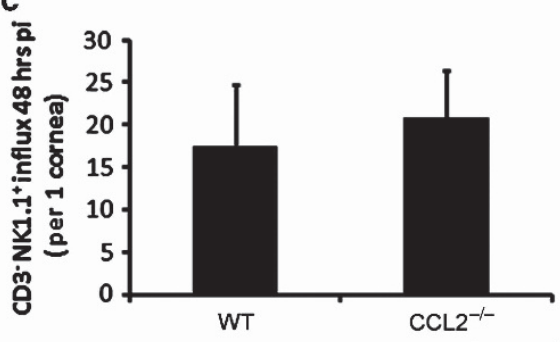

e

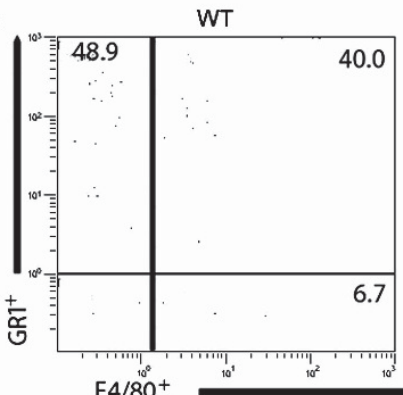

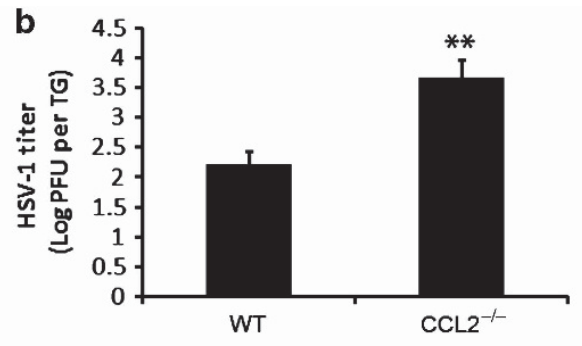

d

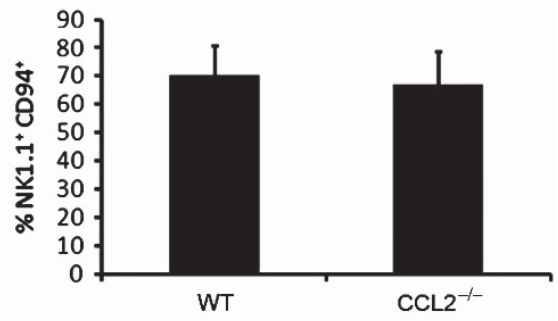

$\mathrm{CCL}^{-1-}$

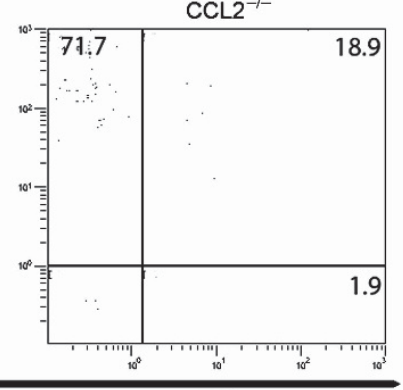

$\mathbf{f}$

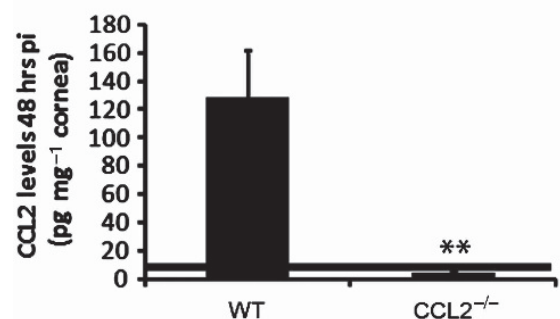

g

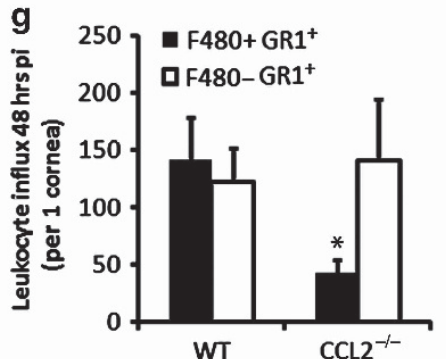

Figure 4 CCL2 production drives inflammatory monocyte recruitment. CCL2 ${ }^{-/-}$and WT mice were infected with 1,000 PFU (plaque-forming units) HSV-1 (herpes simplex virus type I)/eye and 48 or $120 \mathrm{~h}$ post-infection (pi) corneas (6-8 corneas/group) were harvested and evaluated for viral content in the (a) cornea and (b) trigeminal ganglion (TG), (c-e) leukocyte influx, and (f) chemokine production. Representative histograms depicted in (g). Values summarize two independent experiments and are represented as the mean \pm s.e.m. ${ }^{* *} P<0.01 ;{ }^{*} P<0.05$ when the wild-type (WT) and CCL2 ${ }^{-/-}$ groups were compared. Dotted line, limit of detection.

IFN- $\alpha$ and CCL2 mRNA was evaluated. CCL2 transcript levels rose 10 -fold $6 \mathrm{~h}$ post treatment but returned to near baseline $6 \mathrm{~h}$ later, suggesting that IFN alone could drive CCL2 production (Figure 7e). To further solidify this point, WT mice topically treated with rIFN- $\alpha$ had significantly higher levels of CCL2 $24 \mathrm{~h}$ post treatement than PBS-treated controls and $\mathrm{CD} 118^{-/-}$mice treated with PBS or IFN (Figure 7f).

\section{DISCUSSION}

We have previously shown IFI-16 was responsible for the recognition of HSV in epithelial tissue and once activated, the sensor drove IRF-3-dependent IFN production critical in containing viral replication. ${ }^{9}$ However, we did not explore the contribution of infiltrating leukocytes. ${ }^{9}$ In the study described herein, we have identified inflammatory monocytes $\left(\mathrm{F} 4 / 80^{+} \mathrm{Gr} 1^{+}\right)$as the $\mathrm{BM}$ component of innate immunity within the cornea proper that contributes to HSV-1 surveillance. To substantiate the BM arm of innate immunity, a loss of any part of the CCL2-inflammatory monocyte response results in a significant reduction in the host's ability to contain viral replication.

The chemokine CCL2 is widely studied because of its up-regulation in autoimmune diseases, tumors, and infections. ${ }^{17,28,29}$ CCL2 attributes can be favorable or unfavorable to the host. From a negative aspect, the chemokine facilitates tumor metastasis and HIV entry into the CNS. ${ }^{30,31}$ However, CCL2 is also needed in muscle repair ${ }^{32}$ and as we have found, is required 

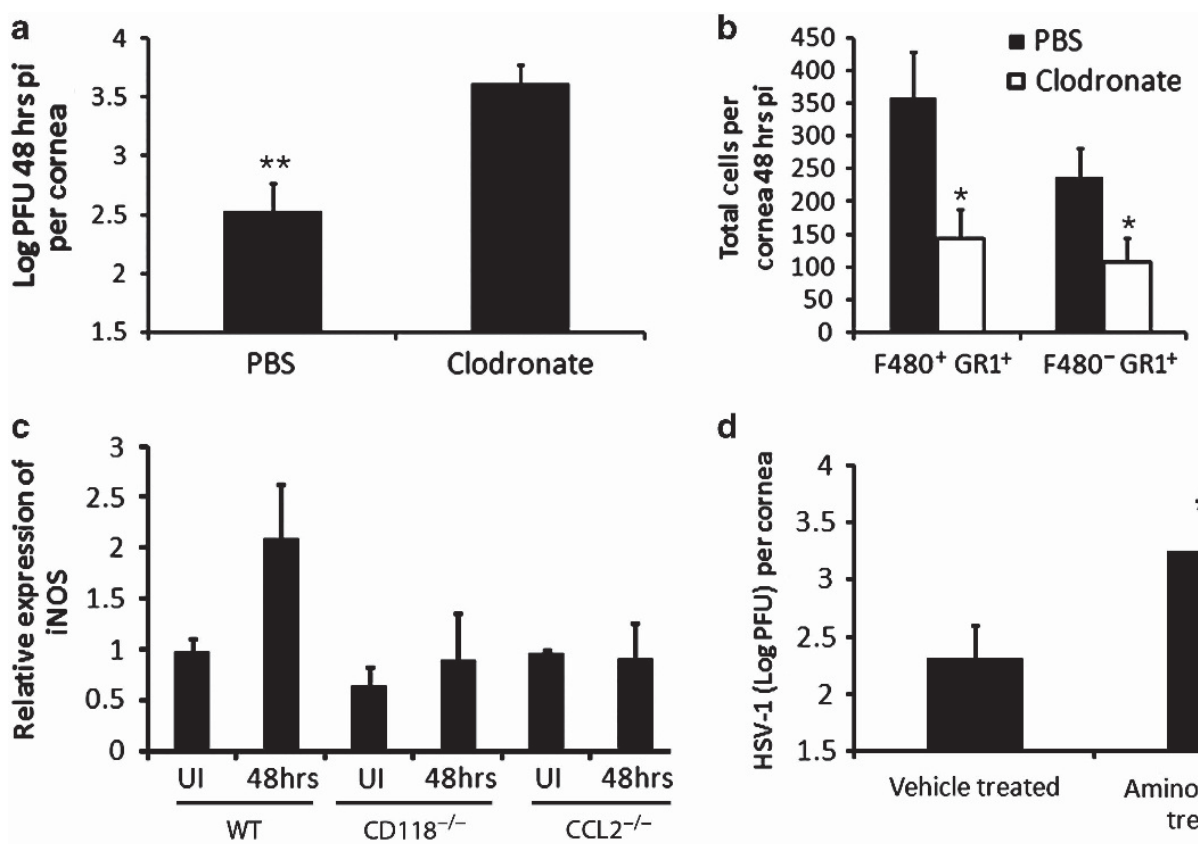

d
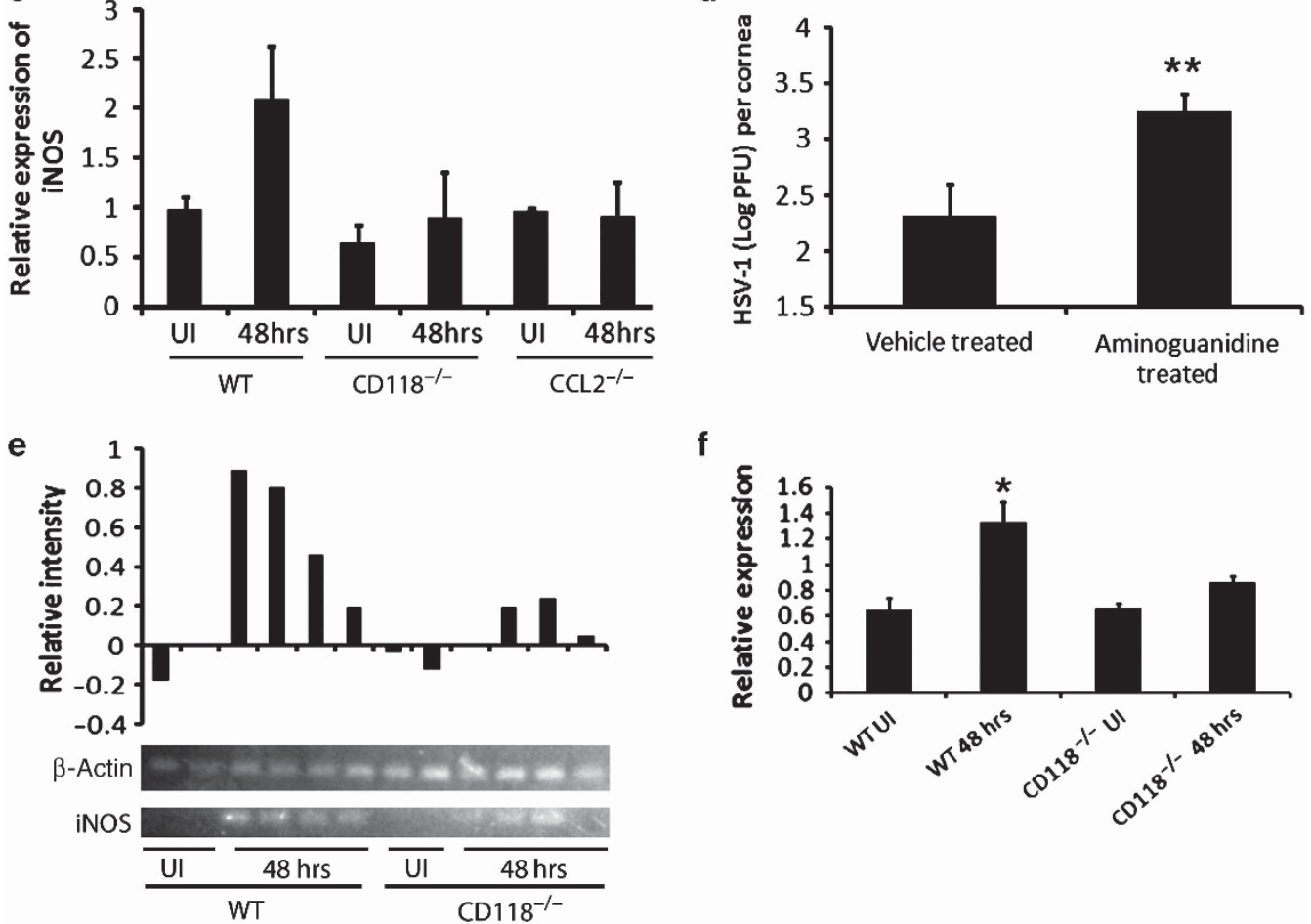

f

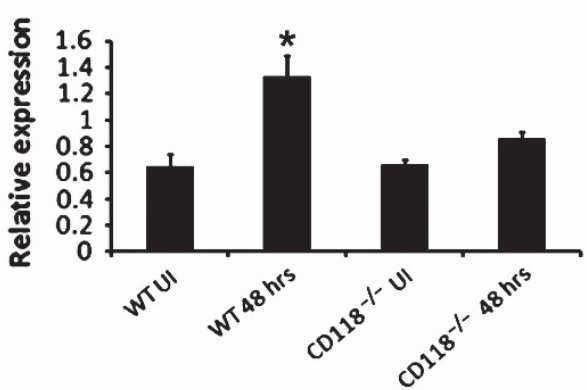

Figure 5 Clodronate depletion of inflammatory monocytes significantly reduces immune control of herpes simplex virus (HSV) infection due to loss of the antiviral agent nitric oxide. Wild-type (WT) mice were infected with HSV-1 and then treated with a subconjunctival injection of clodronate or phosphate-buffered saline (PBS) containing liposomes. Twenty-four hours later, the liposome treatment was repeated. Forty-eight hours post infection (pi), WT mice were euthanized and corneal viral content was quantified by (a) plaque assay or immune cell infiltration was assessed by (b) flow cytometry. Graphs are represented as the mean \pm s.e.m. ( $n=6-8$ corneas/group). ${ }^{\star \star} P<0.01 ;{ }^{*} P<0.05$. (c, d) RT-PCR (PCR with reverse transcriptase) products were analyzed by gel electrophoresis and data and image are representative of two independent experiments. (c) Normalized (to $\beta$-actin) intensity of each sample can be seen above gel and (d) mean normalized intensity \pm s.e.m. of the entire experiment is expressed in (d). (e) Forty-eight hours pi (1,000 PFU (plaque-forming units) HSV-1/eye), mRNA was isolated from whole corneas of WT, CD118 ${ }^{-/-}$, and CCL2 ${ }^{-/-}$mice $(n=3-10)$ and RT-PCR was performed to determine the presence of inducible nitric oxide synthase (iNOS). The results were normalized to uninfected (UI) controls and the housekeeping gene $\beta$-actin. (d) WT mice were topically treated with aminoguanidine $(0.05 \mathrm{mg})$ or vehicle three times daily starting $48 \mathrm{~h}$ before infection with HSV-1 (1,000 PFU/eye). Viral titers in the cornea were evaluated $48 \mathrm{~h}$ pi and compared with vehicle-treated WT mice ( $n=6-8$ corneas/group). Data is presented as the mean \pm s.e.m. ${ }^{* \star} P<0.01$.

in the cornea to recruit inflammatory monocytes to contain HSV-1 replication. Additionally, CCL2 production has been shown to be regulated by both TNF- $\alpha$ and STAT- 2 signals. ${ }^{33,34}$ However, we show that the CCL2 upstream promoter contains an IFN-responsive element, and cells treated with recombinant IFN alone up-regulate CCL2 mRNA. Such results imply multiple host signals elicit CCL2 expression dependent upon the initiating stimulus. We hypothesize that the timing of CCL2 production is facilitated by different signals and is likely tissue specific. This notion is best observed in $\mathrm{CD} 118^{-/-}$mice that lack downstream IFN signals. Forty-eight hours pi, CD118 ${ }^{-/-}$ mice produced very low levels of CCL2 in the cornea; however, by 5 days pi, CCL 2 concentrations were significantly higher in CD $118^{-/-}$mice than WT controls. Furthermore, we have previously shown in peripheral nervous system tissue such as the trigeminal ganglia that there were no identified differences in CCL2 production comparing HSV-1 infected WT with CD $118^{-/-}$mice. $^{7}$ This was in stark contrast to the brain stem where the only difference in levels of the chemokine was detected 5 days pi when $\mathrm{CD} 118^{-/-}$mouse brain stem possessed significantly more CCL2. ${ }^{7}$ Thus, the regulation of CCL2 is complex and warrants further inspection. Furthermore, while we 

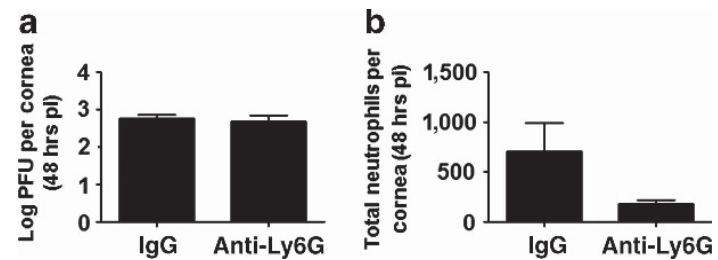

Figure 6 Loss of neutrophils does not enhance corneal susceptibility to herpes simplex virus (HSV) infection. Wild-type (WT) mice were infected with HSV-1 (1,000 PFU (plaque-forming units)/eye) and then given a subconjunctival injection of either immunoglobulin $\mathrm{G}(\mathrm{IgG})$ control or anti-Ly6G antibody. Forty-eight hours post infection (pi), (a) viral content was evaluated by plaque assay and presented as the Log PFU/cornea \pm s.e.m. ( $n=7 /$ group, two experiments). To confirm depletion, flow cytometry was used to evaluate $(\mathbf{b})$ total neutrophils residing within the cornea and is representative of two independent experiments. Values are presented as the total neutrophils \pm s.e.m.

found no precedent for enhanced $\mathrm{p} 65$ nuclear translocation in uninfected CD $118^{-/-}$mice, an immediate early gene of HSV-1, ICP0, has been shown to inhibit NF- $\mathrm{BB}$ signaling by reducing specific TLR adaptor protein levels possibly explaining the loss of nuclear $\mathrm{p} 65$ in infected $\mathrm{CD} 118^{-/-}$corneas in which viral levels were much higher than WT controls. ${ }^{35}$

Although the role of inflammatory monocytes in controlling parasitic and bacterial infections is well described, ${ }^{36,37}$ the contribution of these cells in HSV infection was ambiguous. Most studies would suggest neutrophils and NK cells are the predominant immune cell required to contain HSV replication during the innate immune response. ${ }^{38-40}$ However, we show in mice that recruit inflammatory monocytes with far less efficiency (CD $118^{-/-}$and CCL2 $2^{-/-}$mice) than WT animals, such mice suffer from significantly more virus in the cornea that correlates with a reduction in NO levels. Although NO is likely only one of several viral replication inhibitors secreted by infiltrating monocytes (e.g., TNF- $\alpha$ ), ${ }^{41}$ its ability to antagonize viral replication has been previously noted. ${ }^{14,24,42}$ To further substantiate the role of inflammatory monocytes in innate immunity of the cornea, localized clodronate depletion was performed and resulted in significantly higher HSV-1 titers. The one caveat to these results is that the treatment resulted in a loss of neutrophils $\left(\mathrm{F} 4 / 80^{-} \mathrm{Gr} 1^{+}\right)$as well. However, CD118 $8^{-/-}$and CCL2 $2^{-/-}$mice have similar numbers of neutrophils despite significantly more infectious virus in the cornea than those of WT controls. Additionally, specific depletion of neutrophils in WT mice did not result in an increase in viral titers recovered from the cornea following HSV-1 infection. This would suggest and be supported by previous work with herpetic lesions in the skin showing that depletion of $\mathrm{Ly} 6 \mathrm{G}^{+}$cells (neutrophils) did not compromise the anti-viral response. ${ }^{22}$ However, this study did suggest the loss of $\mathrm{Gr}^{+}$cells (includes both neutrophils and inflammatory monocytes) resulted in a deficiency in viral containment. ${ }^{22}$ Thus, the role of neutrophils in HSV surveillance of the cornea is likely only minimal at best with a notable contribution to ocular pathology. ${ }^{43}$ Additionally, viral resistance mediated by NK cells during acute HSV infection of the cornea is likely minimal compared with that of inflammatory monocytes and a later response than that of monocytes. This is evident in CCL2 $2^{-1-}$ mice that are compromised in viral surveillance $48 \mathrm{~h}$ pi but activity (CD94 expression ${ }^{20}$ ) and total numbers of NK cells does not differ from those of WT controls. Studies implicating NK cells in ocular surveillance have used depletion techniques to confirm their role within the first $96 \mathrm{~h} ;{ }^{40}$ however, the antibody targeting NK cells (anti-ASGM-1) has also been reported to reduce inflammatory monocyte recruitment into the cornea proper. ${ }^{40,44}$ Furthermore, we identified that the major contribution of inflammatory monocytes occurs within the first $48 \mathrm{~h}$ after infection. Thus, it is unclear what role, if any, NK cells contribute to the earliest phases of the inflammatory monocyte-driven innate immunity within the cornea and how these responses are orchestrated.

We surmise inflammatory monocytes and IFI-16-driven IFN production act together to contain viral replication in the cornea and likely other epithelial tissues. ${ }^{9}$ These two arms of the innate immune response are required during acute HSV infection and as such would be potential targets for vaccine development. Current attempts of incorporating HSV glycoproteins in vaccine designs have failed, ${ }^{45,46}$ suggesting additional factors are likely required to provide protective immunity. Thus, attenuated strains of $\mathrm{HSV}^{47}$ that provide host epithelial cells with viral DNA to activate IFI-16-driven cascades would likely facilitate a more robust immune response strengthening the overall vaccine, while reducing the establishment of latency. ${ }^{48}$ Furthermore, the widely used adjuvant, alum, is known to excite IRF-3-dependent cascades owing to the release of host DNA from dying cells. ${ }^{49}$ We hypothesize that this could be due, at least in part, to IFI16 activity as a result of the ability of the protein to respond to both host and viral $\mathrm{DNA}^{50}$ and thus, boost the overall immune response to the vaccine. Consequently, activating the IFI-16 pathway may be more fruitful in preventing early viral replication and establishment of latency owing to its significant role in initiating the innate immune response to HSV- 1 and HSV-2 in epithelial tissue. $^{9}$

In conclusion, we propose that IFI-16 activates IFN production and NF- $\kappa B$ signaling through a STING-dependent manner in response to HSV-1 within resident cells of the cornea and likely other epithelial tissues. ${ }^{9}$ Up-regulated products of IFN signaling such as CCL2, PKR, and RNase L facilitate an antiviral state in the cornea. The CCL2 chemokine gradient recruits inflammatory monocytes to the infectious lesion, where the leukocytes secrete compounds such as NO to antagonize HSV-1 replication. IFN-responsive proteins such as PKR and RNase L initiate an antiviral state within infected and uninfected cells of the cornea to further inhibit viral spread (Figure 8). These two orchestrated processes act synergistically to contain HSV-1 replication in the cornea even in the absence of TLR signaling.

\section{MATERIALS AND METHODS}

Mice and virus. C57BL/6J WT Trif ${ }^{-1-}\left(\right.$ Ticam $^{-1-}$; C57BL/6J background) and CCL2 ${ }^{-/-}$mice were purchased from Jackson Laboratory and housed in the Dean McGee Eye Institute's and Presbyterian Health Foundation's animal facilities alongside $\mathrm{MyD} 88^{-/-}, \mathrm{CD} 118^{-/-}$, and STING $^{-/-}$mice. ${ }^{51-53}$ Animal treatment was consistent with the National 
a

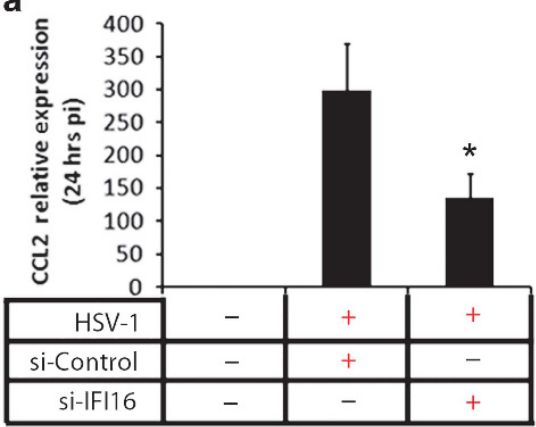

b

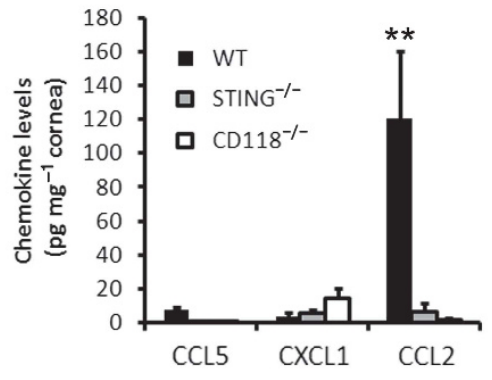

C

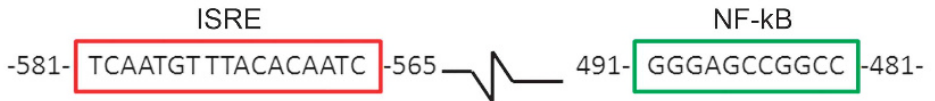

d UI $44 \mathrm{hrs}$

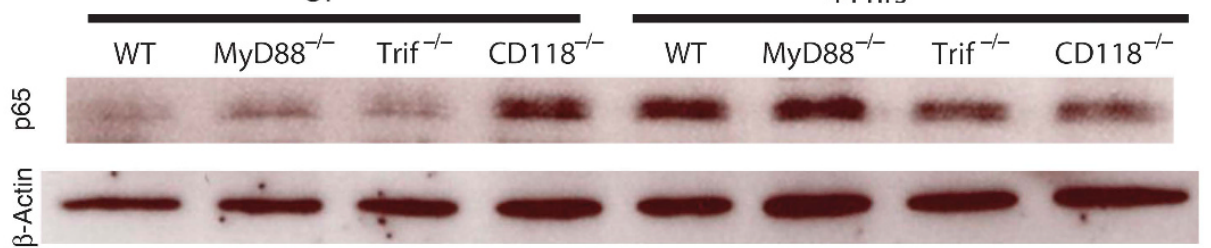

e

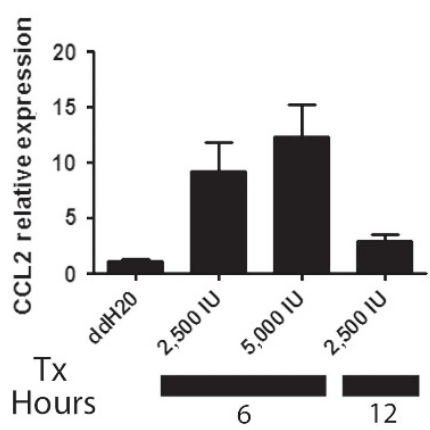

f

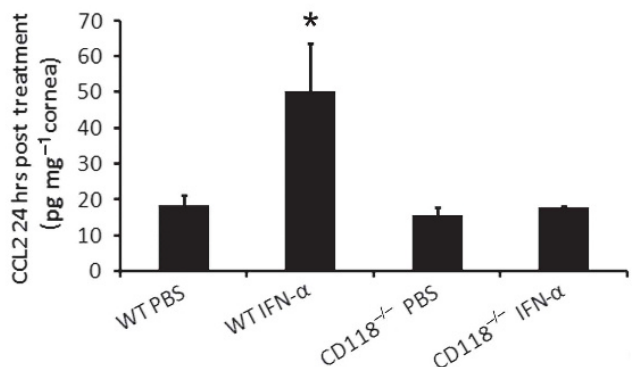

Figure 7 IFI-16 drives CCL2 production by way of type I interferon (IFN). (a) Transfected human corneal epithelial (THCE) cells were transfected with control or siRNA specific to IFI-16 and infected with herpes simplex virus type 1 (HSV-1). Twenty-four hours post infection (pi), mRNA transcript expression was evaluated for CCL2 and normalized to uninfected (UI) controls and the housekeeping gene $\beta$-actin. Results are expressed as the mean \pm S.e.m. (b) STING ${ }^{-/-}$, CD118 ${ }^{-/-}$, and wild-type (WT) mice $(n=4-8)$ were infected with 1,000 PFU (plaque-forming units)/eye. Forty-eight hours pi chemokine content was evaluated by suspension array and is presented as the mean $\mathrm{pg} \mathrm{mg}^{-1} \pm$ s.e.m. (c) Evaluation of the upstream promoter of

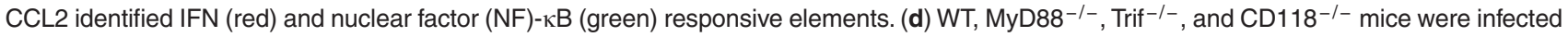
and NF-kB nuclear translocation was assessed $44 \mathrm{~h}$ pi by Western blot and compared with UI controls. Image is representative of two independent experiments. (e) THCE cells $(n=9)$ were treated with rIFN- $\alpha$ and CCL2 mRNA transcript assessed at 6 or $12 \mathrm{~h}$ post treatment. Results were normalized to $\mathrm{ddH}_{2} \mathrm{O}$ controls and the housekeeping gene $\beta$-actin. Values are expressed as the mean \pm s.e.m. of $2-3$ independent experiments. (f) To confirm IFN was responsible for driving CCL2, WT, and CD118-/- mice were treated with phosphate-buffered saline (PBS) or 30,0000 U rIFN- $\alpha$. Twenty-four hours later, chemokine levels were assessed and are presented as the mean \pm s.e.m. of three independent experiments of $2-3$ corneas $/ g r o u p . ~{ }^{*} P<0.01$; ${ }^{*} P<0.05$. ISRE, IFN-stimulated regulatory element; IU, units; Tx, treatment.

Institutes of Health Guidelines on the Care and Use of Laboratory Animals. All experimental procedures were approved by the University of Oklahoma Health Sciences Center and Dean A. McGee Eye Institutes' Institutional Animal and Care Use Committees. HSV-1 McKrae was passaged as previously described. 7

In vivo HSV-1 infection. Six- to ten-week-old male and female mice were anesthetized by an intraperitoneal (i.p.) injection of xylazine $\left(6.6 \mathrm{mg} \mathrm{kg}^{1}\right)$ and ketamine $\left(100 \mathrm{mg} \mathrm{kg}^{1}\right)$. Corneas were scarified with a 25 gauge $11 / 2^{\prime \prime}$ needle, and the tear film was blotted. HSV-1 McKrae was resuspended $(1,000 \mathrm{PFU}$ (plaque-forming units)/eye) in $3 \mu \mathrm{ls}$ of sterile $1 \times \mathrm{PBS}$ and topically applied onto each cornea.
Plaque assays. The corneas of infected mice were harvested at designated times, resuspended in RPMI 1640 media supplemented with 10\% fetal bovine serum, antibiotic/antimycotic, and gentamicin (normal media, Invitrogen, Grand Island, NY), and homogenized with a tissue miser for approximately $20-30 \mathrm{~s}$ as previously described. ${ }^{7}$ Supernatant was then clarified with a $10,000 \times g$ spin for $1.5 \mathrm{~min}$ and serially diluted onto a confluent lawn of HSV-1 susceptible green monkey kidney (Vero) cells. Plaques were allowed to develop for $24-36 \mathrm{~h}$ and then counted with the aid of an inverted Zeiss microscope (Thornwood, NY).

BM chimeras. Six- to ten-week-old male and female mice were lethally irradiated with two 650-rad doses of $\gamma$ irradiation separated by $4 \mathrm{~h}$. 


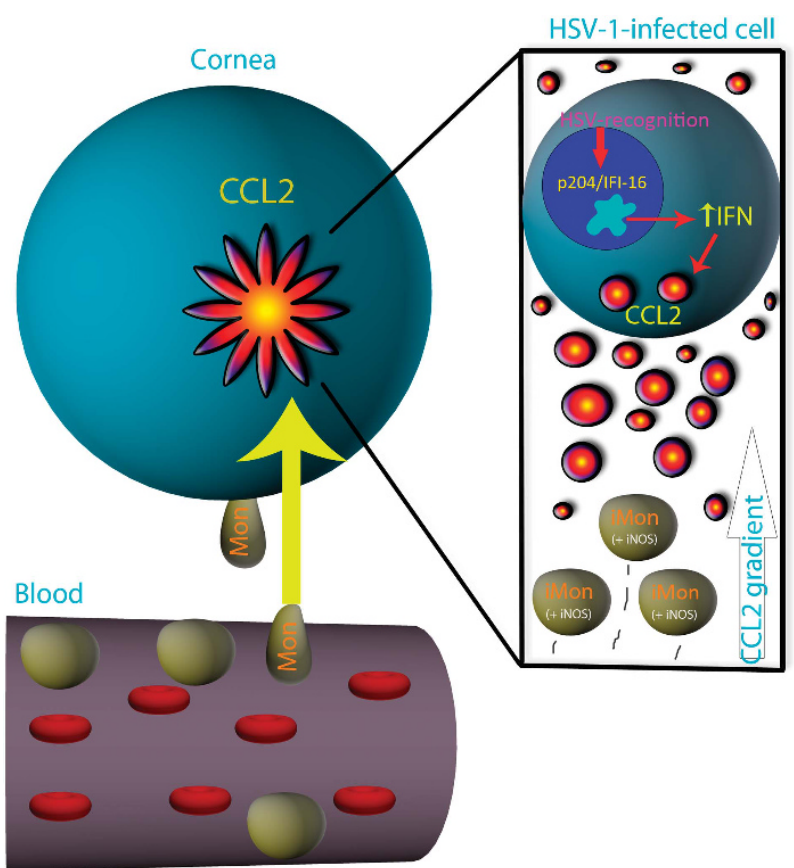

Figure 8 Schematic representation of innate immunity in the cornea in response to herpes simplex virus type 1 (HSV-1). IFI-16/p204 binds HSV-1 and subsequently activates interferon (IFN) production through an IRF-3 (interferon regulatory factor 3)-STING-dependent mechanism and nuclear factor (NF)- $\mathrm{\kappa B}$ signaling to induce antiviral proteins such as protein kinase $R$ and RNAse $L$ as well as CCL2. The localized CCL2 gradient chemoattracts circulating inflammatory monocytes (iMon) from the blood to the site of infection in the cornea, where the monocytes secrete nitric oxide (NO) to further block HSV-1 spread. These finelytuned responses (bone marrow and resident) work in concert to orchestrate acute resistance to HSV-1 in the cornea and are first initiated by $\mathrm{p} 204$. iNOS ${ }^{+}$, inducible NO synthase-expressing cell.

Irradiated mice were then given $3 \times 10^{6} \mathrm{BM}$ cells by retro-orbital injection isolated from either CD $118^{-/-}$or WT femurs. The injected BM cells were then given 10 weeks to completely reconstitute the $\mathrm{BM}$ as previously described. ${ }^{9,54}$ To confirm chimerism, flow analysis was performed on circulating leukocytes and was found to be consistently $>95 \%$ successful implant. Mice were then infected as previously described and the indicated test performed.

ELISAs and bioplex assays. At the indicated time pi, mice were euthanized, and the corneas were harvested. The corneas were then resuspended in normal media containing a $1 \times$ protease inhibitor cocktail (Calbiotech, Spring Valley, CA) on ice. Following homogenization, homogenates were clarified by a $10,000 \times g$ centrifugation for $1 \mathrm{~min}$. Supernatants were evaluated for CXCL1, CCL2, and CCL5, by a Bioplex suspension array (BioRad, Hercules, CA) per manufacturers' instructions. For rIFN- $\alpha$ experiments, 30,000 units of purified IFN or PBS was topically applied to corneas.

Flow cytometry. At the appointed time pi, mice were euthanized and corneas harvested. The corneas were then subjected to a $1 \mathrm{mg} \mathrm{ml}^{-1}$ type I collagenase digestion for $1.5-2 \mathrm{~h}$ at $37^{\circ} \mathrm{C}$. Following digestion, single cell suspensions were labeled with monoclonal antibodies and analyzed using a Coulter Epics XL flow cytometer (BD Biosciences (San Jose, CA), Beckman Coulter (Brea, CA)). The absolute number of cells residing in the cornea was determined as previously described. ${ }^{7}$

iNOS inhibition. Mice were anesthetized and topically treated three times daily with $0.05 \mathrm{mg}$. of iNOS inhibitor, aminoguanidine (SigmaAldrich, St Louis, MO), resuspended in $1 \times \mathrm{PBS}^{24}$ After two days, mice were infected as previously described. Forty-eight hours pi, mice were euthanized and viral loads in the cornea were evaluated by plaque assay. Mice were treated starting two days before infection up to $48 \mathrm{~h}$ pi.

In vitro transfection and infection. Human corneal epithelial cells (a gift from Dr Jerry Shay, UT-Southwestern) were grown in six-well plates to $50-70 \%$ confluency in keratinocyte media containing bovine pituitary extract and recombinant epithelial growth factor (Invitrogen). The cells were then transfected with 2 or 4 pmols of either nonspecific (5'-UUCUCCGAACGUGUCA CGUTT-3') or siRNA specific to IFI-16 (5'-GGUGCUGAACGCAAC AGAAUCAUUU-3') (Invitrogen, medium GC-rich content backbone) in serum-free keratinocyte media. Following a 4-h incubation, serum-free media was removed and replaced with normal media. Twenty-four hours post transfection, cells were infected at a multiplicity of infection of .001 of HSV-1 McKrae. Media was then replaced after $1 \mathrm{~h}$ at $37^{\circ} \mathrm{C}$, and the cells and supernatant harvested $24 \mathrm{~h}$ pi.

Macrophage/neutrophil depletion. Mice were anesthetized and infected with 1,000 PFU/eye HSV-1. Thirty minutes after infection, mice were given a $10 \mu \mathrm{l}$ subconjunctival injection of PBS liposomes, clodronate liposomes, IgG control antibody, or anti-Ly6G (eBioscience, San Diego, $\mathrm{CA}$ ). For clodronate experiments, mice were given a second injection $24 \mathrm{~h}$ later. Forty-eight hours pi, viral content was evaluated by plaque assay. Macrophage/neutrophil depletion was determined by flow cytometry.

RT-PCR. Corneas were harvested at the indicated time pi, and mRNA transcript was isolated as previously described. ${ }^{9}$ iNOS primers were purchased from Origene (Rockville, MD) and the other primer sequences can be seen below.

\begin{tabular}{ll}
\hline Primer & Sequence \\
\hline m $\beta$-ActinF & 5'-CTTCTACAATGAGCTGCGTGTG-3' \\
m $\beta$-ActinR & 5'-TTGAAGGTCTCAAACATGATCTGG-3' \\
h $\beta$-ActinF & 5'-AGCCTCGCCTTTGCCGA-3' \\
h $\beta$-ActinR & 5'-CATGTCGTCCCAGTTGGTGAC-3' \\
hCCL2F & 5'-ATGAAAGTCTCTGCCGCCCTTCTGT-3' \\
hCCL2R & 5'-CCTCTGCACTGAGATCTTCCTATTGGTG-3' \\
\hline
\end{tabular}

Abbreviations: $h$, human; $m$, mouse.

Statistical analysis. Statistical analysis was conducted using a GBSTAT one-way analysis of variance followed by the ad hoc Tukey's $t$ test in experiments with more than two groups. Significance was defined as a $P$ value less than 0.05 throughout the paper.

\section{ACKNOWLEDGMENTS}

We thank Julie Tran, Sara Moore, Linh Sramek, and Gabby Nguyen for technical support and Dr Helen Rosenberg, Dr Russell Vance, and Dr Shizuro Akira for the CD118-/-, STING ${ }^{-/-}$, and MyD88-/mice respectively. We also like to thank Roche Diagnostics $\mathrm{GmbH}$ for clodronate liposomes. Principal support for the study was from NIH Al053108 to DJJC. Additional support includes an OUHSC Presbyterian Health Foundation Presidential Professorship award to DJJC, NIH/NCRR P20 RR017703, and a senior investigator award (to DJJC) from Research to Prevent Blindness.

\section{DISCLOSURE}

The authors declare no conflicts of interest.

(c) 2013 Society for Mucosal Immunology

\section{REFERENCES}

1. Conrady, C.D., Drevets, D.A. \& Carr, D.J. Herpes simplex type I (HSV-1) infection of the nervous system: is an immune response a good thing? J. Neuroimmunol. 220, 1-9 (2010).

2. Khanna, K.M., Lepisto, A.J. \& Hendricks, R.L. Immunity to latent viral infection: many skirmishes but few fatalities. Trends Immunol. 25, 230-234 (2004). 
3. Duan, R., de Vries, R.D., Osterhaus, A.D., Remeijer, L. \& Verjans, G.M. Acyclovir-resistant corneal HSV-1 isolates from patients with herpetic keratitis. J. Infect Dis. 198, 659-663 (2008).

4. Larkin, D.F. Corneal transplantation for herpes simplex keratitis. Br. J. Ophthalmol. 82, 107-108 (1998).

5. Smith, R.L., Morroni, J. \& Wilcox, C.L. Lack of effect of treatment with penciclovir or acyclovir on the establishment of latent HSV-1 in primary sensory neurons in culture. Antiviral Res. 52, 19-24 (2001).

6. Wakim, L.M., Jones, C.M., Gebhardt, T., Preston, C.M. \& Carbone, F.R. CD8(+) T-cell attenuation of cutaneous herpes simplex virus infection reduces the average viral copy number of the ensuing latent infection. Immunol. Cell Biol. 86, 666-675 (2008).

7. Conrady, C.D., Thapa, M., Wuest, T. \& Carr, D.J. Loss of mandibular lymph node integrity is associated with an increase in sensitivity to HSV-1 infection in CD118-deficient mice. J. Immunol. 182, 3678-3687 (2009).

8. Leib, D.A., Harrison, T.E., Laslo, K.M., Machalek, M.A., Moorman, N.J. \& Virgin, H.W. Interferons regulate the phenotype of wild-type and mutant herpes simplex viruses in vivo. J. Exp. Med. 189, 663-672 (1999).

9. Conrady, C.D., Zheng, M., Fitzgerald, K.A., Liu, C. \& Carr, D.J. Resistance to HSV-1 infection in the epithelium resides with the novel innate sensor, IFI-16. Mucosal Immunol. 5, 173-183 (2012).

10. Reading, P.C., Whitney, P.G., Barr, D.P., Smyth, M.J. \& Brooks, A.G. NK cells contribute to the early clearance of HSV-1 from the lung but cannot control replication in the central nervous system following intranasal infection. Eur. J. Immunol. 36, 897-905 (2006).

11. van Lint, A., Ayers, M., Brooks, A.G., Coles, R.M., Heath, W.R. \& Carbone, F.R. Herpes simplex virus-specific CD8+ T cells can clear established lytic infections from skin and nerves and can partially limit the early spread of virus after cutaneous inoculation. J. Immunol. 172, 392-397 (2004).

12. Knickelbein, J.E., Khanna, K.M., Yee, M.B., Baty, C.J., Kinchington, P.R. \& Hendricks, R.L. Noncytotoxic lytic granule-mediated CD8+ T cell inhibition of HSV-1 reactivation from neuronal latency. Science $\mathbf{3 2 2}$ 268-271 (2008).

13. Chisholm, S.E., Howard, K., Gomez, M.V. \& Reyburn, H.T. Expression of ICPO is sufficient to trigger natural killer cell recognition of herpes simplex virus-infected cells by natural cytotoxicity receptors. J. Infect Dis. 195, 1160-1168 (2007).

14. Croen, K.D. Evidence for antiviral effect of nitric oxide. Inhibition of herpes simplex virus type 1 replication. J. Clin. Invest. 91, 2446-2452 (1993).

15. Kodukula, P., Liu, T., Rooijen, N.V., Jager, M.J. \& Hendricks, R.L. Macrophage control of herpes simplex virus type 1 replication in the peripheral nervous system. J. Immunol. 162, 2895-2905 (1999).

16. Fernandez, E.J. \& Lolis, E. Structure, function, and inhibition of chemokines. Annu. Rev. Pharmacol. Toxicol. 42, 469-499 (2002).

17. Morrison, B.E., Park, S.J., Mooney, J.M. \& Mehrad, B. Chemokinemediated recruitment of NK cells is a critical host defense mechanism in invasive aspergillosis. J. Clin. Invest. 112, 1862-1870 (2003).

18. Yoshimura, T., Robinson, E.A., Tanaka, S., Appella, E., Kuratsu, J. \& Leonard, E.J. Purification and amino acid analysis of two human gliomaderived monocyte chemoattractants. J. Exp. Med. 169, 1449-1459 (1989).

19. Taub, D.D., Sayers, T.J., Carter, C.R. \& Ortaldo, J.R. Alpha and beta chemokines induce NK cell migration and enhance NK-mediated cytolysis. J. Immunol. 155, 3877-3888 (1995).

20. Ho, E.L., Heusel, J.W., Brown, M.G., Matsumoto, K., Scalzo, A.A. \& Yokoyama, W.M. Murine Nkg2d and Cd94 are clustered within the natural killer complex and are expressed independently in natural killer cells. Proc. Natl. Acad. Sci. USA 95, 6320-6325 (1998).

21. Yu, J. et al. CD94 surface density identifies a functional intermediary between the CD56bright and CD56dim human NK-cell subsets. Blood 115, 274-281 (2010).

22. Wojtasiak, M. et al. Depletion of Gr-1+, but not Ly6G+, immune cells exacerbates virus replication and disease in an intranasal model of herpes simplex virus type 1 infection. J. Gen. Virol. 91, 2158-2166 (2010).

23. Cheng, H., Tumpey, T.M., Staats, H.F., van Rooijen, N., Oakes, J.E. \& Lausch, R.N. Role of macrophages in restricting herpes simplex virus type 1 growth after ocular infection. Invest. Ophthalmol. Vis. Sci. 41, 1402-1409 (2000).

24. Benencia, F., Courreges, M.C., Gamba, G., Cavalieri, H. \& Massouh, E.J. Effect of aminoguanidine, a nitric oxide synthase inhibitor, on ocular infection with herpes simplex virus in Balb/c mice. Invest. Ophthalmol. Vis. Sci. 42, 1277-1284 (2001).
25. Farlik, M. et al. Nonconventional initiation complex assembly by STAT and NF-kappaB transcription factors regulates nitric oxide synthase expression. Immunity 33, 25-34 (2010).

26. Fantuzzi, L. et al. Phosphatidylcholine-specific phospholipase $\mathrm{C}$ activation is required for CCR5-dependent, NF-kB-driven CCL2 secretion elicited in response to HIV-1 gp120 in human primary macrophages. Blood 111, 3355-3363 (2008)

27. Unterholzner, L. et al. IFI16 is an innate immune sensor for intracellular DNA. Nat. Immunol. 11, 997-1004 (2010).

28. Metelitsa, L.S. et al. Natural killer T cells infiltrate neuroblastomas expressing the chemokine CCL2. J. Exp. Med. 199, 1213-1221 (2004).

29. Huang, D.R., Wang, J., Kivisakk, P., Rollins, B.J. \& Ransohoff, R.M. Absence of monocyte chemoattractant protein 1 in mice leads to decreased local macrophage recruitment and antigen-specific T helper cell type 1 immune response in experimental autoimmune encephalomyelitis. J. Exp. Med. 193, 713-726 (2001).

30. Qian, B.Z. et al. CCL2 recruits inflammatory monocytes to facilitate breast-tumour metastasis. Nature 475, 222-225 (2011).

31. Eugenin, E.A., Osiecki, K., Lopez, L., Goldstein, H., Calderon, T.M. \& Berman, J.W. CCL2/monocyte chemoattractant protein-1 mediates enhanced transmigration of human immunodeficiency virus (HIV)-infected leukocytes across the blood-brain barrier: a potential mechanism of HIV-CNS invasion and NeuroAIDS. J. Neurosci. 26, 1098-1106 (2006).

32. Lu, H., Huang, D., Ransohoff, R.M. \& Zhou, L. Acute skeletal muscle injury: CCL2 expression by both monocytes and injured muscle is required for repair. FASEB J. 25, 3344-3355 (2011).

33. Khorooshi, R., Babcock, A.A. \& Owens, T. NF-kappaB-driven STAT2 and CCL2 expression in astrocytes in response to brain injury. J. Immunol. 181, 7284-7291 (2008).

34. Bonello, G.B., Pham, M.H., Begum, K., Sigala, J., Sataranatarajan, K. \& Mummidi, S. An evolutionarily conserved TNF-alpha-responsive enhancer in the far upstream region of human CCL2 locus influences its gene expression. J. Immunol. 186, 7025-7038 (2011).

35. van Lint, A.L. et al. Herpes simplex virus immediate-early ICPO protein inhibits Toll-like receptor 2-dependent inflammatory responses and NF-kappaB signaling. J. Virol. 84, 10802-10811 (2010).

36. Dunay, I.R. et al. Gr1(+) inflammatory monocytes are required for mucosal resistance to the pathogen Toxoplasma gondii. Immunity 29, 306-317 (2008).

37. Kim, Y.G. et al. The Nod2 sensor promotes intestinal pathogen eradication via the chemokine CCL2-dependent recruitment of inflammatory monocytes. Immunity 34, 769-780 (2011).

38. Tumpey, T.M., Chen, S.H., Oakes, J.E. \& Lausch, R.N. Neutrophilmediated suppression of virus replication after herpes simplex virus type 1 infection of the murine cornea. J. Virol. 70, 898-904 (1996).

39. Siebens, H., Tevethia, S.S. \& Babior, B.M. Neutrophil-mediated antibodydependent killing of herpes-simplex-virus-infected cells. Blood 54, 88-94 (1979).

40. Frank, G.M., Buela, K.A., Maker, D.M., Harvey, S.A. \& Hendricks, R.L. Early responding dendritic cells direct the local NK response to control herpes simplex virus 1 infection within the cornea. J. Immunol. 188, 1350-1359 (2012)

41. Rossol-Voth, R., Rossol, S., Schutt, K.H., Corridori, S., de Cian, W. \& Falke, D. In vivo protective effect of tumour necrosis factor alpha against experimental infection with herpes simplex virus type 1. J. Gen. Virol. 72 (Pt 1), 143-147 (1991).

42. Karupiah, G., Xie, Q.W., Buller, R.M., Nathan, C., Duarte, C. \& MacMicking, J.D. Inhibition of viral replication by interferon-gammainduced nitric oxide synthase. Science 261, 1445-1448 (1993).

43. Yan, X.T., Tumpey, T.M., Kunkel, S.L., Oakes, J.E. \& Lausch, R.N. Role of MIP-2 in neutrophil migration and tissue injury in the herpes simplex virus-1-infected cornea. Invest. Ophthalmol. Vis. Sci. 39, 1854-1862 (1998).

44. Nishikado, H., Mukai, K., Kawano, Y., Minegishi, Y. \& Karasuyama, H. NK cell-depleting anti-asialo GM1 antibody exhibits a lethal off-target effect on basophils in vivo. J. Immunol. 186, 5766-5771 (2011).

45. Belshe, R.B. et al. Efficacy results of a trial of a herpes simplex vaccine. N. Engl. J. Med. 366, 34-43 (2012).

46. Corey, L. et al. Recombinant glycoprotein vaccine for the prevention of genital HSV-2 infection: two randomized controlled trials. Chiron HSV Vaccine Study Group. JAMA 282, 331-340 (1999). 
47. Halford, W.P., Puschel, R., Gershburg, E., Wilber, A., Gershburg, S. \& Rakowski, B. A live-attenuated HSV-2 ICPO virus elicits 10 to 100 times greater protection against genital herpes than a glycoprotein $\mathrm{D}$ subunit vaccine. PLoS One 6, e17748 (2011).

48. Lin, W.R., Jennings, R., Smith, T.L., Wozniak, M.A. \& Itzhaki, R.F. Vaccination prevents latent HSV1 infection of mouse brain. Neurobiol. Aging 22, 699-703 (2001).

49. Marichal, T. et al. DNA released from dying host cells mediates aluminum adjuvant activity. Nat. Med. 17, 996-1002 (2011).

50. Liu, C.J., Wang, H. \& Lengyel, P. The interferon-inducible nucleolar p204 protein binds the ribosomal RNA-specific UBF1 transcription factor and inhibits ribosomal RNA transcription. EMBO J. 18, 2845-2854 (1999).
51. Garvey, T.L. et al. Inflammatory responses to pneumovirus infection in IFN-alpha beta R gene-deleted mice. J. Immunol. 175, 4735-4744 (2005).

52. Sauer, J.D. et al. The N-ethyl-N-nitrosourea-induced Goldenticket mouse mutant reveals an essential function of Sting in the in vivo interferon response to Listeria monocytogenes and cyclic dinucleotides. Infect. Immun. 79, 688-694 (2011).

53. Adachi, O. et al. Targeted disruption of the MyD88 gene results in loss of IL-1- and IL-18-mediated function. Immunity 9, 143-150 (1998).

54. Esplin, B.L., Welner, R.S., Zhang, Q., Borghesi, L.A. \& Kincade, P.W. A differentiation pathway for B1 cells in adult bone marrow. Proc. Natl. Acad. Sci. USA 106, 5773-5778 (2009). 